\title{
Heat Transfer Characteristics of a Polymer-Based Roll-to-Roll Microchannel Heat Exchanger
}

\author{
Heng Wang, Samuel D. Marshall, Rerngchai Arayanarakool, Lakshmi Balasubramaniam, \\ Niven Singh Virik, Poh Seng Lee, Peter C.Y. Chen \\ National University of Singapore \\ Lower Kent Ridge, Singapore \\ mpewhe@nus.edu.sg
}

\begin{abstract}
Polymer-based heat exchangers are advantageous for corrosion resistance, light weight, and low costs. Microchannel heat exchangers are promising for material saving and high heat transfer capacity. Curved channels can promote the secondary fluid flow to enhance the effectiveness of heat transfer. Roll to roll technology makes it possible to roll thin-film layers up to form curved channels inside the layers. Combining all the strengths mentioned above, this research comes up with a polymer-based roll-to-roll microchannel heat exchanger with three different designs. Through numerical simulations, this study analyses the heat transfer characteristics of those three heat exchanger designs. Dean numbers and Nusselt numbers are calculated to evaluate the formation of Dean Vortices and the effectiveness of heat transfer. Simulation results demonstrate that the formation of Dean Vortices induced through the roll-to-roll microchannel structure helps to improve the heat transfer compared with equivalent straight-channel heat exchangers. In addition, this study calculates not only the Nusselt numbers but also the Thermal Performance Factors to take into account the high pressure drops in the microchannel. Finally, the efficiencies of heat transfer of the three heat exchanger designs are compared with each other.
\end{abstract}

Keywords: heat transfer, microchannel, polymer-based, roll to roll, Dean Vortices, heat exchangers

\section{Introduction}

In daily life, energy use is a real concern as there should be a balance between its production and consumption. It is ideal to make full use of energy or to recover energy, for example, recycling residual heat from industrial waste water. In this process, a heat exchanger, whose function is to transfer heat between solid and fluid, or among fluids with different temperatures, plays an important role in sustainable energy utilization. With the steady developments of micro/nanotechnology, new materials, and advanced manufacturing methods, many novel heat exchanger designs [1-3] have been proposed. In this study, a polymer-based roll-to-roll microchannel heat exchanger is designed with three different configurations. Through numerical simulations, this study explores their potentials in enhancing heat transfer compared with straight microchannel heat exchanger designs, and comparisons are made among those three different configurations.

From the perspective of materials, the main focus of this study is polymers. When utilized as the material of heat exchangers, polymers have limitations including low thermal conductivity and low operating temperatures [4]. However, compared with other materials, polymers have many advantages such as low density, corrosion resistance, ease of manufacturing, and low costs [4]. Specifically, this study assumes PMMA as the material of the microchannel heat exchangers.

Microchannel heat exchanger is also receiving more and more attention for its space savings, high efficiency of heat transfer, and reduced weight [5], with the increase of issues such as material savings, increased energy demands, and space limitation. Microchannel heat exchangers make it possible that the design can be more compact due to the small size of the channels. In addition, microchannel heat exchanger leads to large heat transfer areas per volume unit and accordingly, a higher heat transfer coefficient [6].

For the overall structures of the microchannel heat exchanger, the curved channel is employed to improve heat transfer between the microchannels, since curved channels will induce the secondary flow in the form of Dean Vortices [7]. As a beneficial fluid flowing mechanism for heat exchanger designs, those Dean Vortices promote the fluid mixing inside 
microchannels and then enhance heat transfer. With the developments of roll to roll technology, this novel manufacturing method has been employed to roll thin films up in several practical applications such as polymer solar cells [8-9] and transport electrodes [10]. Since the main focus of this research is on PMMA-based microchannel heat exchangers, it is a worth to explore whether the curved microchannels fabricated through roll-to-roll technology could further enhance the heat transfer between the microchannels. This study combines all the advantageous features mentioned above to design a polymer-based roll-to-roll microchannel heat exchanger. However, for the heat exchanger design, there are several approaches of rolling the PMMA layers up. Therefore, this study comes up with three polymer-based microchannel heat exchanger designs with various rolling-up mechanisms. Through numerical simulations, this study compares the effectiveness of heat transfer among three heat exchanger designs.

\section{Model development and analysis}

\subsection{Modelling}

In order to compare the effectiveness of heat transfer of roll-to-roll microchannel heat exchangers with straight microchannel heat exchangers, this paper comes up with three different designs as shown in Figure 1, where the blue part represents cold fluid, red part represents hot fluid, and the outside transparent layers are PMMA films with microchannels. Similar to the coil heater, the first design (Figure 1a) shows PMMA films with cold fluid microchannels immersed in hot fluid. Base on the mechanisms of commonly-used spiral heat exchangers, two other roll-to-roll microchannel heat exchangers are presented: in the second heat exchanger design (Figure 1b), hot and cold fluid microchannels are designed alternatively in the same PMMA layer; for the third heat exchanger design (Figure 1c), two separate layers with hot fluid microchannels and cold fluid microchannels are designed separately and then rolled up together. Cross sections of three heat exchanger designs (Figure 1d-1f) are shown below the drawings respectively.

For all the three designs, thickness of the PMMA film is fixed as $1 \mathrm{~mm}$, and the channel length is $157.15 \mathrm{~mm}$, which is the length of five circuits of the second heat exchanger design. Cross section geometry of the microchannel is circular with a diameter of $0.6 \mathrm{~mm}$. In the first design, there are 10 microchannels. In the second design, the number of cold fluid microchannels is 10 , while for hot fluid, it is 11. In the third design, the number of either cold fluid or hot fluid microchannels is 10. The gap between the microchannel layers in the first design is fixed as $1 \mathrm{~mm}$. However in the second and third design, the microchannel layers are rolled tightly without any gap. In the first design, the cold fluid flows inwards through the microchannels. For the second design and third design, the cold fluid flows inwards through the microchannels, while the hot fluid flows outwards through the microchannels. This paper also compares the degree of curved channels through using two different diameters of the first circuit of the microchannel (Dfc): $5 \mathrm{~mm}$ and $8 \mathrm{~mm}$ (these two values guarantee the formation of Dean Vortices theoretically). Dimensions of straight microchannel heat exchangers for comparison in this study are set to be the same as the roll-to-roll heat exchangers. In this study, SolidWorks is employed to develop the models and then imported to CFD software FLUENT to calculate the improvements of heat transfer.

\subsection{Assessment criteria}

In this study, three parameters are adopted to characterize the performances of fluid flow and the heat transfer of the heat exchangers: the average Dean Number $(\overline{\mathrm{De}})$, the average Nusselt Number $(\overline{\mathrm{Nu}})$, and the Thermal Performance Factor (TPF).

Firstly, in order to explore the fluid flowing inside the roll-to-roll microchannel, in this study, the average Dean Number $(\overline{\mathrm{De}})$ is employed to analyze the secondary flow of the fluid in the form of Dean Vortices, as what has been studied by Dean [11], which is defined as:

$$
\overline{\mathrm{De}}=\operatorname{Re} \sqrt{\frac{\mathrm{D}_{\mathrm{h}}}{2 \overline{\mathrm{R}}}}
$$

where Re is the Reynold number, $D_{h}$ is the hydraulic diameter of the channel, $\bar{R}$ is the average radius of curvature. 


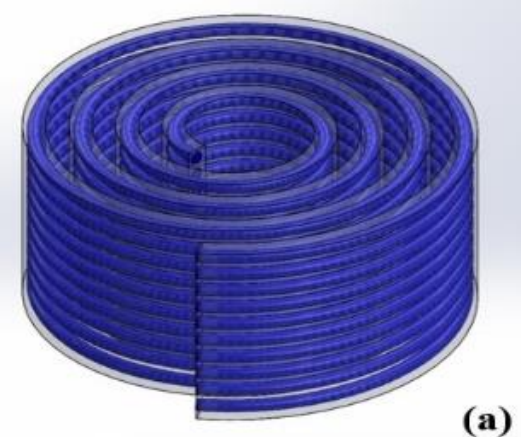

(a)

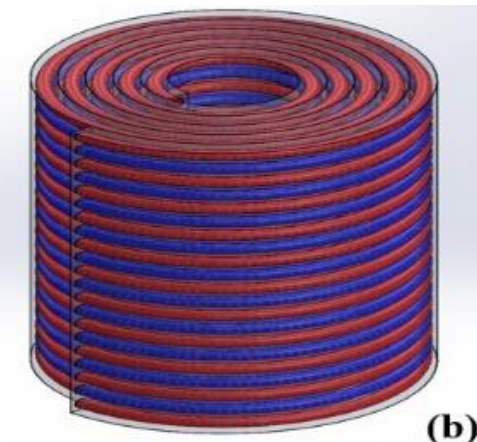

(b)

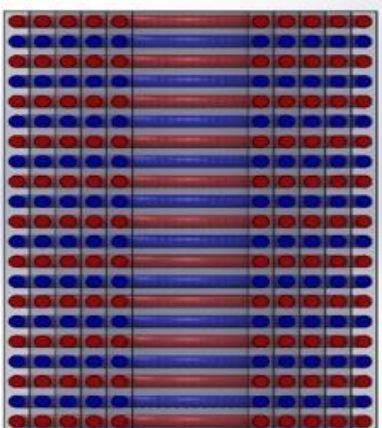

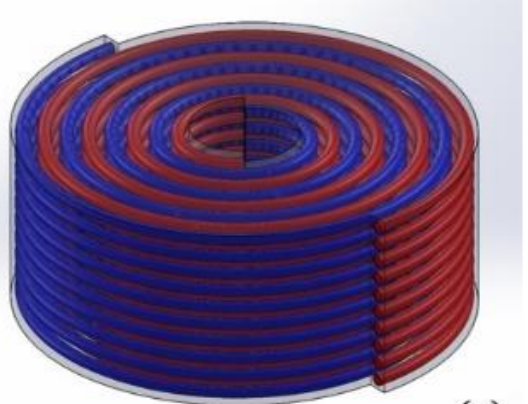

(c)

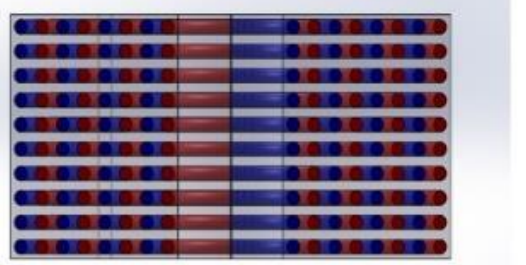

(f)

Fig. 1: Three different roll to roll microchannel heat exchanger designs: (a) Roll-to-roll microchannel heat exchanger immersed in hot fluid, (b) Roll-to-roll microchannel heat exchanger with cold fluid and hot fluid in the same layer, (c) Roll-to-roll microchannel heat exchanger with cold and hot fluid in different layers and then rolled up together. (d-f) cross sections of three heat exchanger designs.

For the behaviour of heat transfer between the hot and cold microchannel, the Nusselt Number $(\mathrm{Nu})$, which shows the ratio of the convective heat transport to the conductive heat transport of a fluid is employed. This study uses a more commonly-used value for microchannel case, the average Nusselt Number ( $\overline{\mathrm{Nu}})$ [12], to evaluate the heat transfer of microchannels, which is defined as:

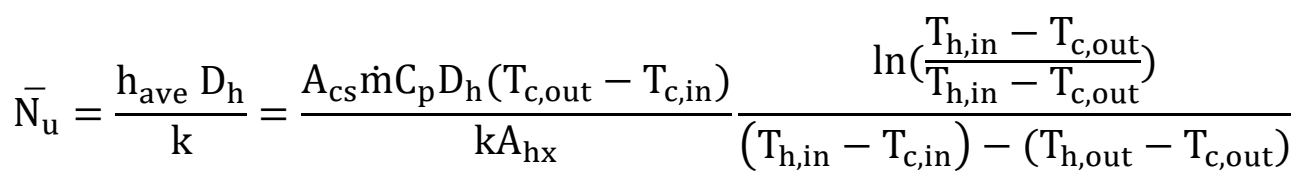

where, $\mathrm{h}_{\mathrm{ave}}$ is the average convective heat transfer coefficient, $\mathrm{k}$ is the thermal conductivity of the fluid, $\mathrm{A}_{\mathrm{cs}}$ is the cross section area, $m$ is the mass flow rate of the fluid, $\mathrm{C}_{\mathrm{p}}$ is the specific heat capacity of the fluid, $\mathrm{A}_{\mathrm{hx}}$ is the heat transfer area, $T_{c, \text { out }}$ is the average temperature of the cold fluid outlet, $T_{c, i n}$ is the average temperature of the cold fluid inlet, $T_{h, \text { out }}$ is the average temperature of the hot fluid outlet, $\mathrm{T}_{\mathrm{h}, \mathrm{in}}$ is the average temperature of the hot fluid inlet.

However, for roll-to-roll microchannel heat exchangers, pressure drop instead of surface roughness is a big concern. Therefore, the Darcy friction factor (f), is employed, which is defined as below. In addition, it is necessary to make a compromise between the Nusselt Number and the friction factor. In this paper, the Thermal Performance Factor (TPF) [13] is calculated to balance between Nusselt Number and pressure drop.

$$
\begin{gathered}
\mathrm{f}=\frac{2 \mathrm{D}_{h} \Delta \mathrm{P}}{\mathrm{L} \rho \mathrm{v}^{2}} \\
\mathrm{TPF}=\frac{\mathrm{Nu}}{\mathrm{f}^{1 / 3}}
\end{gathered}
$$


where $\Delta \mathrm{P}$ is the pressure drop across the microchannel, $\mathrm{L}$ is the length of the microchannel, $\rho$ represents for the density of fluid, and $v$ is the velocity of the fluid.

\subsection{Meshing and boundary conditions}

Figure 2 shows the meshes of three different heat exchanger designs when the Dfc is $8 \mathrm{~mm}$. For each of the three rollto-roll microchannel heat exchanger designs and the corresponding straight microchannel designs, a mesh with a set uniform element size of $2 \times 10-4 \mathrm{~m}$ was applied to the entire model. This value has been decided upon via mesh independency studies. For example, in the second design with Dfc $5 \mathrm{~mm}$, when the inlet velocity is $0.5 \mathrm{~m} / \mathrm{s}$, the comparison results shows that the discrepancies of $\overline{\mathrm{Nu}}$ and TPF between the element size $2 \times 10-4 \mathrm{~m}$ and $4 \times 10-4 \mathrm{~m}$ are only $0.0412 \%$ and $0.0413 \%$. To make the modelling and numerical simulation simpler but reasonable, some assumptions have been made in this study [14]. Due to the channel size and low flow rates, the flow in this study is considered as steady and laminar, and the fluid is assumed as incompressible single-phase water, whose thermophysical properties are assumed to be constant. Besides, at rough surfaces, it is assumed that there is non-slip velocity and temperature. In this study, boundary conditions include inlet velocities of hot fluid and cold fluid with variable range, a hot fluid inlet temperature 350 $\mathrm{K}$, a cold inlet temperature $300 \mathrm{~K}$, and gauge pressures for outlets.

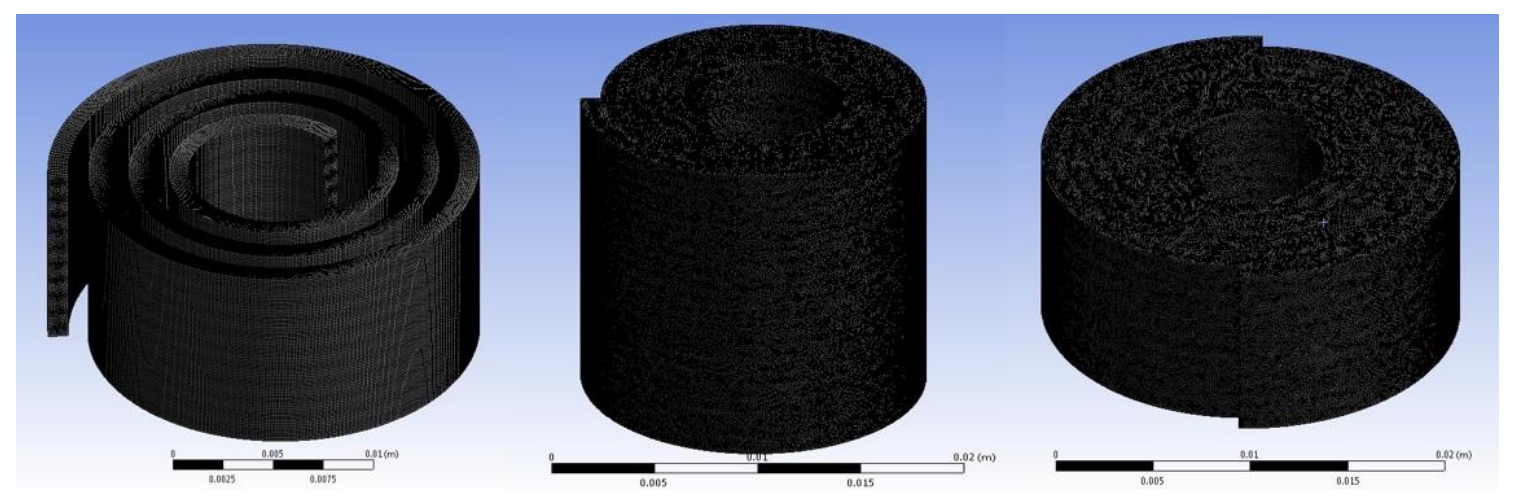

Fig. 2: Meshes of three different roll-to-roll microchannel heat exchanger designs.

\section{Results and discussion}

\subsection{Dean number comparison}

Sudarsan and Ugaz [15] reported that Dean Vortices were formed inside the micro-channels when the Dean numbers were bigger than 10. Table 1 gives the Dean numbers of three roll-to-roll microchannel heat exchanger designs under various inlet velocities. Based on the values, in all cases, there should be Dean Vortices inside the rollto-roll microchannels.

Table 1: Dean numbers of three roll-to-roll microchannel heat exchanger designs under various inlet velocities.

\begin{tabular}{|c|l|c|c|c|}
\hline Inlet Velocity $(\mathrm{m} / \mathrm{s})$ & & 0.1 & 0.5 & 0.8 \\
\hline \multirow{2}{*}{ Design 1 } & $\mathrm{D}_{\mathrm{fc}}=5 \mathrm{~mm}$ & 15.78 & 78.92 & 126.27 \\
\cline { 2 - 5 } & $\mathrm{D}_{\mathrm{fc}}=8 \mathrm{~mm}$ & 14.20 & 71.00 & 113.59 \\
\hline \multirow{2}{*}{ Design 2 } & $\mathrm{D}_{\mathrm{fc}}=5 \mathrm{~mm}$ & 15.39 & 76.94 & 123.10 \\
\cline { 2 - 5 } & $\mathrm{D}_{\mathrm{fc}}=8 \mathrm{~mm}$ & 13.92 & 69.60 & 111.35 \\
\hline \multirow{2}{*}{ Design 3 } & $\mathrm{D}_{\mathrm{fc}}=5 \mathrm{~mm}$ & 15.78 & 78.92 & 126.27 \\
\cline { 2 - 5 } & $\mathrm{D}_{\mathrm{fc}}=8 \mathrm{~mm}$ & 14.20 & 71.00 & 113.59 \\
\hline
\end{tabular}




\subsection{Dean Vortices formation}

From the numerical simulation, the formation of Dean Vortices can be seen clearly. The three cases with the lowest Dean numbers are given below: Figure 3a shows the horizontal velocity vectors on the cross section of the first microchannel heat exchanger design when the inlet velocity is $0.1 \mathrm{~m} / \mathrm{s}$ and the $D_{\mathrm{fc}}$ is $8 \mathrm{~mm}$. Figure $3 \mathrm{~b}$ illustrates the horizontal velocity vectors on the cross section of the second microchannel heat exchanger design when the inlet velocity is $0.1 \mathrm{~m} / \mathrm{s}$ and the $D_{\mathrm{fc}}$ is $8 \mathrm{~mm}$. Figure $3 \mathrm{c}$ gives the horizontal velocity vectors on the cross section of the third microchannel heat exchanger design when the inlet velocity is $0.1 \mathrm{~m} / \mathrm{s}$ and the $D_{\mathrm{fc}}$ is $8 \mathrm{~mm}$. Through plotting the distribution of horizontal velocity vectors on the cross sections of the heat exchanger designs, we can clearly discern that Dean Vortices are starting to form inside the roll-to-roll microchannels.

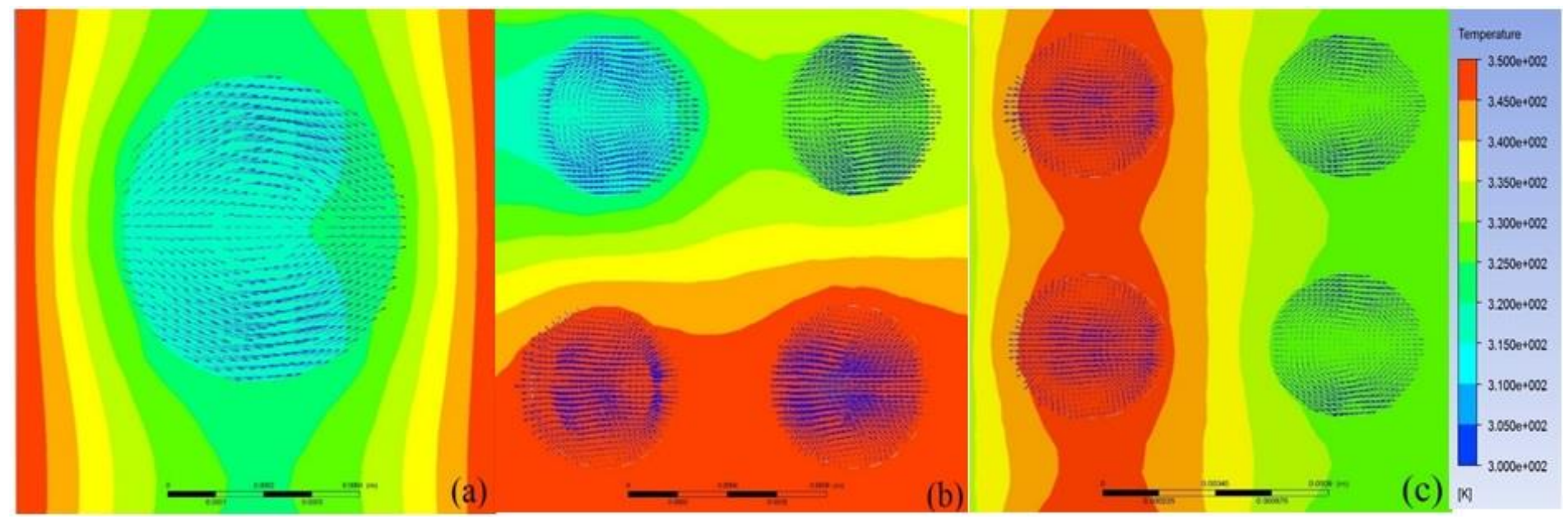

Fig. 3: Horizontal velocity vectors on the cross section of the roll-to-roll microchannel heat exchanger design. (a) The first microchannel heat exchanger design when the inlet velocity is $0.1 \mathrm{~m} / \mathrm{s}$ and the $D_{\mathrm{fc}}$ is $8 \mathrm{~mm}$. (b) The second microchannel heat exchanger design when the inlet velocity is $0.1 \mathrm{~m} / \mathrm{s}$ and the $D_{\mathrm{fc}}$ is $8 \mathrm{~mm}$. (c) The third microchannel heat exchanger design when the inlet velocity is $0.1 \mathrm{~m} / \mathrm{s}$ and the $\mathrm{D}_{\mathrm{fc}}$ is $8 \mathrm{~mm}$.

\subsection{Nusselt Number and TPF improvements}

This study takes the second design with $\mathrm{D}_{\mathrm{fc}} 5 \mathrm{~mm}$ as an example to compare with the corresponding straight microchannel heat exchanger to verify the improvements in effectiveness of heat transfer under various inlet velocities. Figure 4 compares the pressure drop $(\Delta \mathrm{P})$ of cold fluid between the straight microchannel heat exchanger and the roll-toroll microchannel heat exchanger. It can be observed that pressure drops for roll-to-roll microchannel heat exchanger design are higher than for the straight microchannel heat exchanger, particularly for higher inlet velocities. In order to compare the effectiveness of heat transfer, this study calculates the average Nusselt Numbers and TPFs of the second rollto-roll microchannel heat exchanger with $\mathrm{D}_{\mathrm{fc}} 5 \mathrm{~mm}$ and the straight microchannel heat exchanger. Figure 5 compares the Nusselt Numbers of the straight microchannel heat exchanger and the roll-to-roll microchannel heat exchanger, and the percentage of increase. Compared with the straight microchannel heat exchanger, the roll-to-roll design improves the effectiveness of heat transfer greatly. Especially when the inlet velocity is at $0.3 \mathrm{~m} / \mathrm{s}$ or $0.4 \mathrm{~m} / \mathrm{s}$, the Nusselt Number of the roll-to-roll design increases by more than 350\%. Figure 6 compares the TPFs of straight microchannel heat exchanger and roll-to-roll microchannel heat exchanger, and the percentage increase. Although the pressure drops are relatively lower in the straight microchannel heat exchanger design, the substantial heat transfer performance increase induced through the recirculating flows inside the roll-to-roll microchannels makes the roll-to-roll microchannel heat exchanger a better choice. Thus, as shown in Figure 6, the TPFs of roll-to-roll microchannel heat exchangers improve tremendously. 


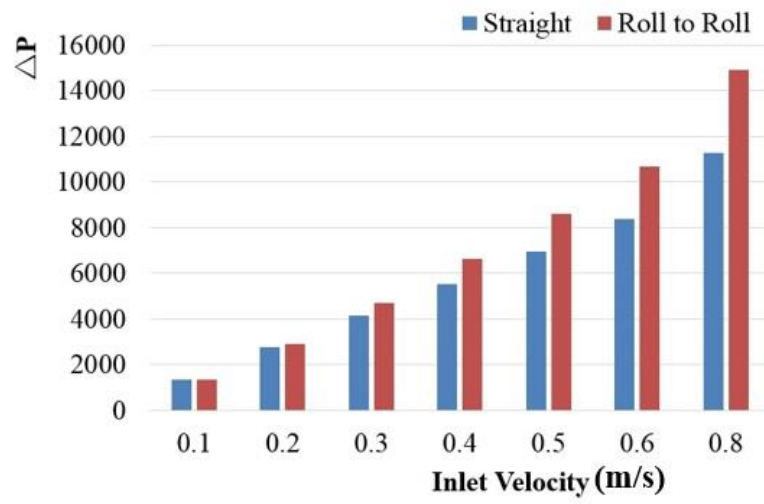

Fig. 4: pressure drop $(\triangle \mathrm{P})$ of cold fluid between the straight microchannel heat exchanger and the second roll-to-roll microchannel heat exchanger with $\mathrm{D}_{\mathrm{fc}} 5 \mathrm{~mm}$.
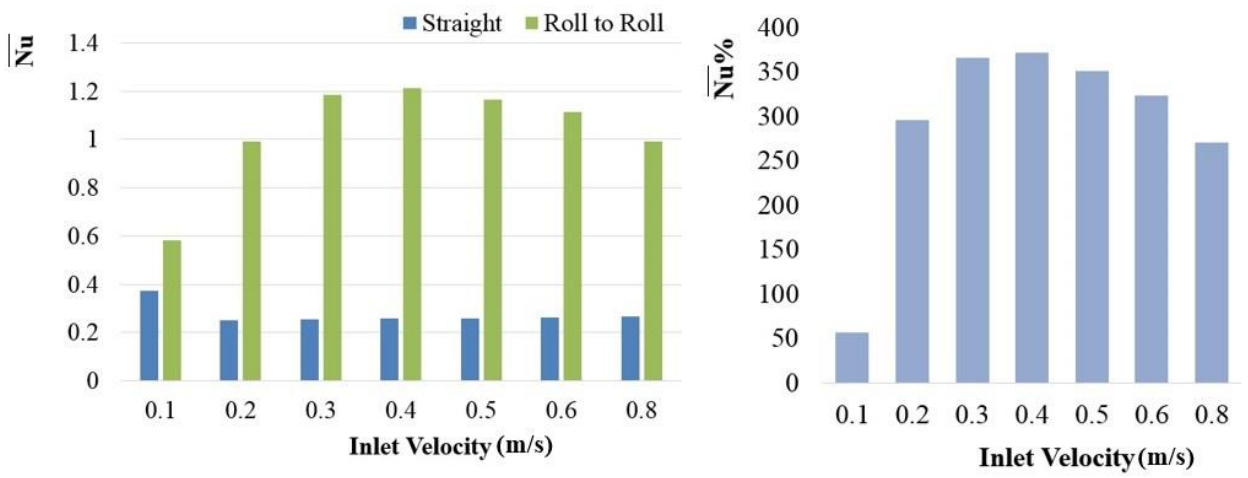

Fig. 5: Nusselt Numbers of the straight microchannel heat exchanger and the second roll-to-roll microchannel heat exchanger with $\mathrm{D}_{\mathrm{fc}}$ $5 \mathrm{~mm}$, and the percentage of increase.
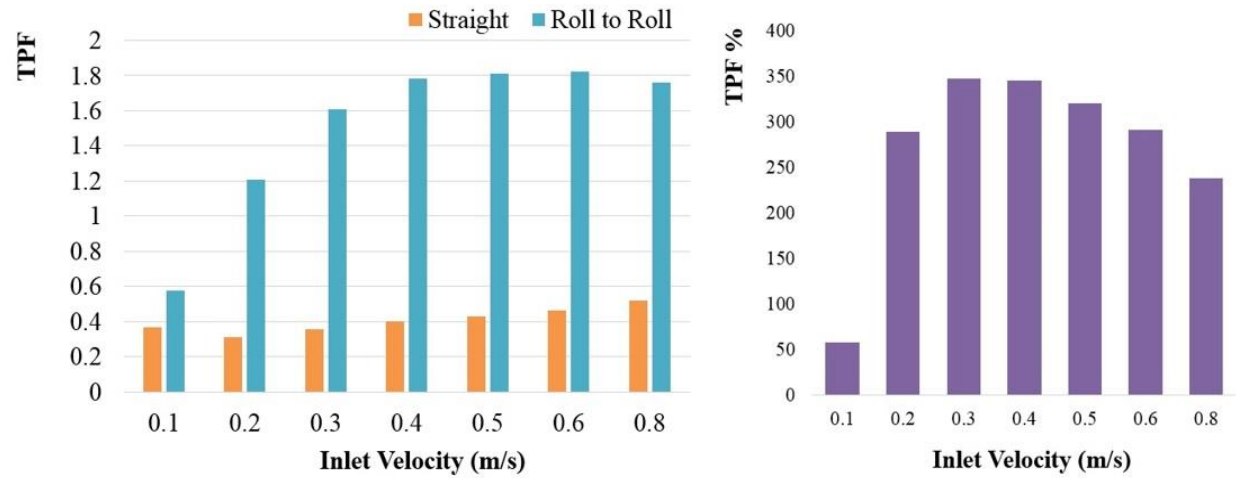

Fig. 6: TPFs of the straight microchannel heat exchanger and the second roll-to-roll microchannel heat exchanger with $\mathrm{D}_{\mathrm{fc}} 5 \mathrm{~mm}$, and the percentage of increase.

\subsection{Nusselt Numbers and TPFs of three heat exchanger design comparison}

Table 2 gives all the Nusselt Numbers and TPFs of three roll-to-roll microchannel heat exchanger designs with $\mathrm{D}_{\mathrm{fc}}$ $5 \mathrm{~mm}$ and $8 \mathrm{~mm}$ under inlet velocities $0.1 \mathrm{~m} / \mathrm{s}, 0.5 \mathrm{~m} / \mathrm{s}$, and $0.8 \mathrm{~m} / \mathrm{s}$. For the first design, there is no substantial advantage compared with the straight microchannel heat exchanger, and when the inlet velocity is $0.1 \mathrm{~m} / \mathrm{s}$, the first heat exchanger design actually behaves worse than the corresponding straight design. However for the second and third heat exchanger designs, the effectiveness of heat transfer increases greatly compared with straight designs, especially for the relatively higher inlet velocities $0.5 \mathrm{~m} / \mathrm{s}$ and $0.8 \mathrm{~m} / \mathrm{s}$. 
Table 2: Nusselt Numbers and TPFs of three roll-to-roll microchannel heat exchanger designs with $\mathrm{D}_{\mathrm{fc}} 5 \mathrm{~mm}$ and $8 \mathrm{~mm}$ under inlet velocities $0.1 \mathrm{~m} / \mathrm{s}, 0.5 \mathrm{~m} / \mathrm{s}$, and $0.8 \mathrm{~m} / \mathrm{s}$.

\begin{tabular}{|c|l|c|c|c|c|c|c|}
\hline & \multicolumn{3}{|c|}{ Nusselt Number } & \multicolumn{3}{c|}{ TPF } \\
\hline \multicolumn{2}{|c|}{ Inlet Velocity (m/s) } & 0.1 & 0.5 & 0.8 & 0.1 & 0.5 & 0.8 \\
\hline \multirow{3}{*}{ Design 1 } & $\mathrm{D}_{\mathrm{fc}}=5 \mathrm{~mm}$ & 0.469 & 0.522 & 0.491 & 0.462 & 0.814 & 0.874 \\
\cline { 2 - 8 } & $\mathrm{D}_{\mathrm{fc}}=8 \mathrm{~mm}$ & 0.175 & 0.420 & 0.257 & 0.170 & 0.637 & 0.435 \\
\cline { 2 - 8 } & Straight & 0.441 & 0.453 & 0.173 & 0.433 & 0.758 & 0.337 \\
\hline \multirow{3}{*}{ Design 2 } & $\mathrm{D}_{\mathrm{fc}}=5 \mathrm{~mm}$ & 0.583 & 1.163 & 0.992 & 0.577 & 1.814 & 1.763 \\
\cline { 2 - 8 } & $\mathrm{D}_{\mathrm{fc}}=8 \mathrm{~mm}$ & 0.534 & 0.908 & 0.796 & 0.526 & 1.405 & 1.404 \\
\cline { 2 - 8 } & Straight & 0.372 & 0.258 & 0.268 & 0.366 & 0.432 & 0.523 \\
\hline \multirow{3}{*}{ Design 3 } & $\mathrm{D}_{\mathrm{fc}}=5 \mathrm{~mm}$ & 0.464 & 0.827 & 0.810 & 0.457 & 1.283 & 1.439 \\
\cline { 2 - 8 } & $\mathrm{D}_{\mathrm{fc}}=8 \mathrm{~mm}$ & 0.537 & 0.775 & 0.664 & 0.528 & 1.202 & 1.172 \\
\cline { 2 - 8 } & Straight & 0.420 & 0.233 & 0.259 & 0.412 & 0.390 & 0.505 \\
\hline
\end{tabular}

In order to plot the improvements more clearly, percentage increases of Nusselt Numbers and TPFs of three heat exchanger designs compared with the straight microchannel heat exchanger designs are shown in Figure 7. For the first roll-to-roll microchannel heat exchanger design, the effectiveness of heat transfer is slightly better than straight microchannel heat exchanger design particularly for lower inlet velocities $0.1 \mathrm{~m} / \mathrm{s}$ and $0.5 \mathrm{~m} / \mathrm{s}$. When the $D_{\mathrm{fc}}$ is $8 \mathrm{~mm}$, the first design behaves worse than straight microchannel heat exchanger. However, for the second and the third heat exchanger design, their heat transfer performances appear to be better than the corresponding straight microchannel heat exchangers. In microchannel heat exchanger designs, employing both hot fluid microchannels and cold fluid microchannels instead of immersing cold fluid microchannels into hot fluid enhances the heat transfer performance greatly, due to the formation of Dean Vortices in both the hot fluid and cold fluid curved microchannels. Comparing the second the third roll-to-roll microchannel heat exchanger design, this study finds that arranging hot fluid and cold fluid microchannels alternatively in the same plane as in the second heat exchanger design is better than in separate planes as in the third heat exchanger design from the perspective of improving heat transfer. Overall, as the most compact design, the second roll-toroll microchannel heat exchanger is the best among the three designs.
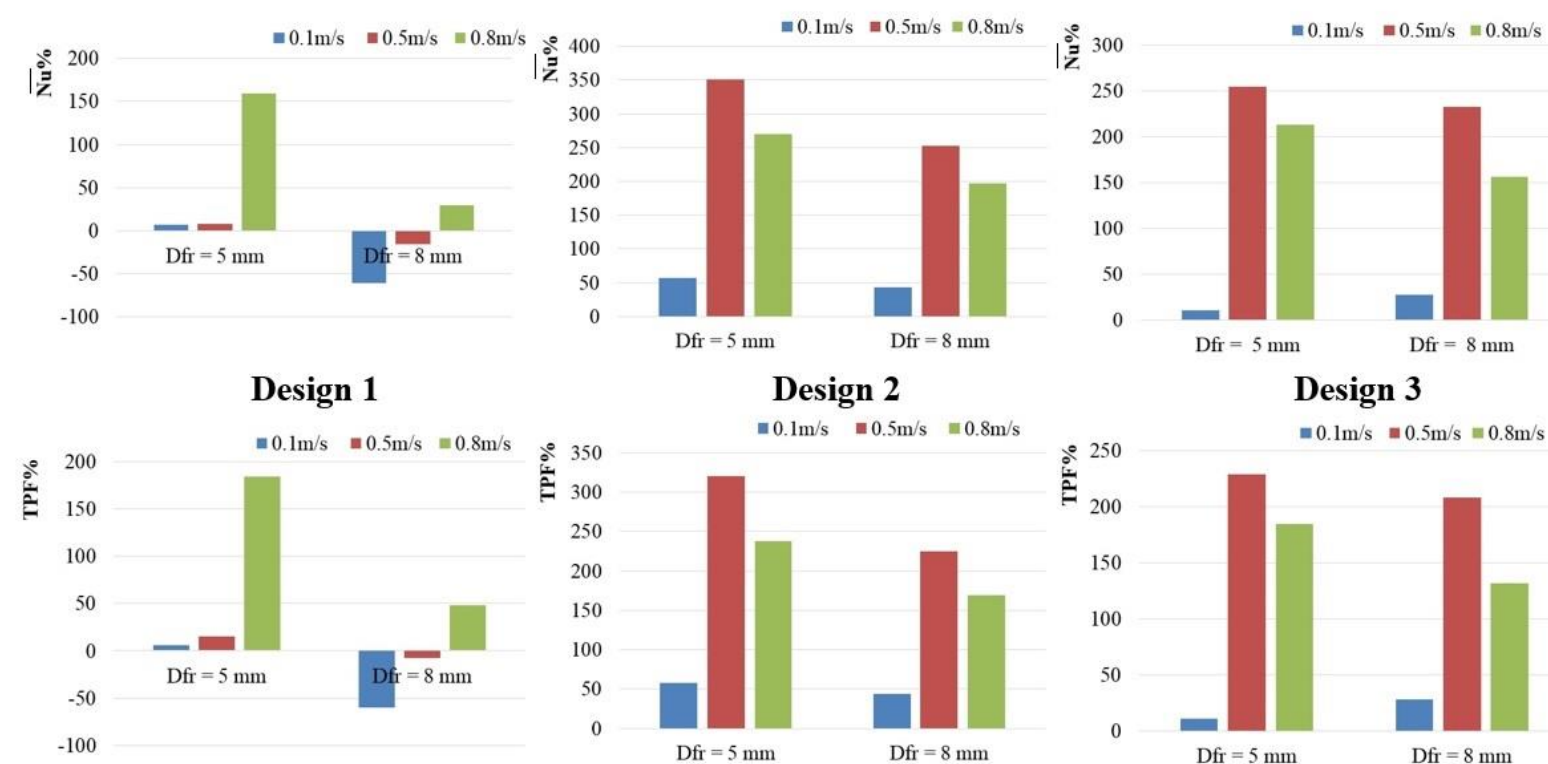

Design 1
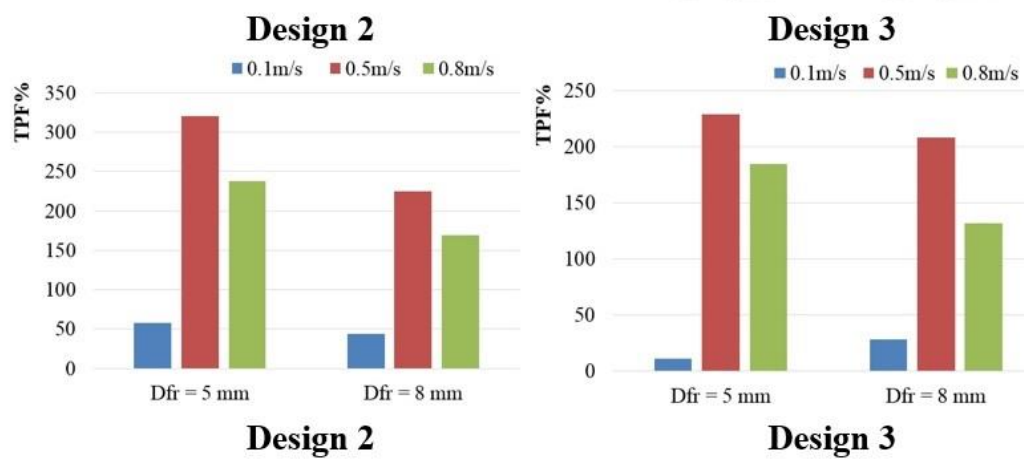

Fig. 7: Percentage increases of Nusselt Numbers and TPFs of three heat exchanger designs with $\mathrm{D}_{\mathrm{fc}} 5 \mathrm{~mm}$ and $8 \mathrm{~mm}$ compared with the corresponding straight microchannel heat exchanger designs under flow rates $0.1 \mathrm{~m} / \mathrm{s}, 0.5 \mathrm{~m} / \mathrm{s}$, and $0.8 \mathrm{~m} / \mathrm{s}$. 


\section{Conclusion}

In this study, a polymer-based roll-to-roll microchannel heat exchanger has been designed with three different configurations. Compared with straight microchannel heat exchangers with same dimensions, due to the Dean Vortices formed inside the roll-to-roll microchannels inducing secondary flows, those newly proposed roll-to-roll microchannel heat exchangers enhance the effectiveness of heat transfer tremendously, expect that for inlet velocities $0.1 \mathrm{~m} / \mathrm{s}$ and $0.5 \mathrm{~m} / \mathrm{s}$, the first heat exchanger with $8 \mathrm{~mm}$ Dfc is a bit worse than the corresponding straight microchannel heat exchanger. Through comparing the heat exchanger designs with each other, this study demonstrates that the second roll-to-roll microchannel heat exchanger has the highest Nusselt Numbers and TPFs among the three designs under inlet velocities $0.1 \mathrm{~m} / \mathrm{s}, 0.5 \mathrm{~m} / \mathrm{s}$, and $0.8 \mathrm{~m} / \mathrm{s}$, which is the best design from the perspective of increasing heat transfer between the microchannels. For heat exchanger designs, the polymer-based roll-to-roll microchannel heat exchanger design presented in this study provides some novel design ideas based on the applications and requirements in practice.

\section{Acknowledgements}

This research grant is supported by the Singapore National Research Foundation under its Environment \& Water Research Programme and administered by PUB, Singapore's national water agency.

\section{References}

[1] C. Harris, M. Despa, K. Kelly, "Design and fabrication of a cross flow micro heat exchanger," Journal of Microelectromechanical Systems, vol. 9, no. 4, pp. 502-508, 2000.

[2] R. J. Robert, B. B. Almand, J. M. Blasi, B. J. Rosen, M. Hartmann, "The design, fabrication, and evaluation of a ceramic counter-flow microchannel heat exchanger," Applied Thermal Engineering, vol. 31, no. 11-12, pp. 20042012, 2011.

[3] H. Lee, K. Saleh, Y. Hwang, R. Radermacher, "Optimization of novel heat exchanger design for the application to low temperature lift heat pump," Energy, vol. 42, no. 1, pp. 204-212, 2012.

[4] J. G. Cevallos, A.E. Bergles, A. Barcohen, P. Rodgers, S. T. Gupta, "Polymer heat exchangers - history, opportunities, and challenges," Heat Transfer Engineering, vol. 33, no. 13, pp. 1075-1093, 2012.

[5] G. K. Mesbah, F. Amir, "A review on microchannel heat exchangers and potential applications," International Journal of Energy Research, vol. 35, pp. 553-582, 2011.

[6] T. Popescu, M. Marinescu, H. Pop, G. Popescu, M. Feidt, "Microchannel heat exchanger - present and perspectives," U.P.B. Science Bulletin, vol. 74, no. 3, 2012.

[7] A. P. Sudarsan, V. M. Ugaz, "Fluid mixing in plannar spiral microchannels," Lab on a Chip, vol. 1, pp. 74-82, 2006.

[8] R. Sondergaard, M. Hosel, D. Angmo, T. T. Larsen, F. C. Krebs, "Roll-to-roll fabrication of polymer solar cells," Materials Today, vol. 15, no. 1-2, 2012.

[9] F. C. Krebs, S. A. Gevorgyan, J. Alstrup, "A roll-to-roll process to flexible polymer solar cells: model studies, manufacture and operational stability studies," Journal of Materials Chemistry, vol. 19, pp. 5442-5451, 2009.

[10] S. Bae, H. Kim, Y. Lee, X. F. Xu, J. S. Park, "Roll-to-roll production of 30-inch graphene films for transparent electrodes," Nature Nanotechnology, vol. 5, pp. 574-578, 2010.

[11] W. R. Dean, "The stream-line motion of fluid in a curved pipe (Second paper)," Philosophical Magazine, vol. 5, no.30, pp. 673-695, 2009.

[12] H. Ghaedamini, P. S. Lee, and C. J. Teo, "Developing Forced Convection in Converging-Diverging Microchannels," International Journal of Heat and Mass Transfer, vol. 65, pp.491-499, 2013.

[13] L. Gong, K. Kota, W. Tao, and Y. Joshi, "Parametric Numerical Study of Flow and Heat Transfer in Microchannels with Wavy Walls," Journal of Heat Transfer, vol. 133, no. 5, 2011.

[14] Y. Q. Luo, W. Y. Liu, L. Wang, W. G. Xie, "Heat and mass transfer characteristics of leaf-vein-inspired microchannels with wall thickening patterns," International Journal of Heat and Mass transfer, vol. 101, pp. 1273$1282,2016$.

[15] A. P. Sudarsan and V. M. Ugaz, "Multivortex micromixing," Proceedings of the National Academy of Sciences of the United States of America, vol. 103, no.19, pp.7228-7233, 2006. 